\title{
Effects of oncological treatment on tooth development in children with brain tumors: Description of cases
}

\section{Wpływ leczenia onkologicznego na rozwój zębów u dzieci z guzem mózgu - opis przypadków}

\author{
Patrycja Proc ${ }^{1, A-D}$, Renata Filipińska, ${ }^{1, B-D}$, Małgorzata Zubowska ${ }^{2, B-D}$ \\ 1 Department of Pediatric Dentistry, Medical University of Lodz, tódź, Poland \\ 2 Department of Pediatrics, Oncology and Hematology, Medical University of Lodz, Łódź, Poland \\ A - research concept and design; $\mathrm{B}$ - collection and/or assembly of data; $\mathrm{C}$ - data analysis and interpretation; \\ $D$ - writing the article; $E$ - critical revision of the article; $F$ - final approval of article
}

Address for correspondence

Patrycja Proc

E-mail: patrycja.proc@umed.lodz.pl

Funding sources

none declared

Conflict of interest

none declared

Received on April 24, 2017

Revised on May 19, 2017

Accepted on June 08, 2017

\begin{abstract}
Despite the fact that the results of oncological treatment improved significantly, cancer remains the main cause of death among children in Poland. Cancer survivors in Łódź have been included in a special preventive program for monitoring late health complications, which is supervised by the Ministry of Health. Seventy-five patients had dental investigations performed and 61 underwent radiographic examinations of their dentition.

The state of dentition in 4 children, who were previously treated for brain tumors years ago, is discussed in this paper. Removal of tumor was the first stage in their treatment; then, the patients were treated according to the Polish protocol for treating brain tumors (etoposide, vincristine, cisplatin, cyclophosphamide). Two of the patients additionally underwent radiotherapy of head (with a dose of 54 Gy). Late dental complications, such as agenesis of teeth, microdontic teeth, teeth with short roots and others were found in all 4 studied patients. It was concluded that patients should be covered with special dental care and treatment during and after cancer therapy.
\end{abstract}

Key words: cancer, children, dental complications

Słowa kluczowe: choroba nowotworowa, dzieci, powikłania stomatologiczne

D0I

$10.17219 / \mathrm{dmp} / 74642$

Copyright

○ 2017 by Wroclaw Medical University

and Polish Dental Society

This is an article distributed under the terms of the

Creative Commons Attribution Non-Commercial License

(http://creativecommons.org/licenses/by-nc-nd/4.0/) 
Brain tumors account for $2 \%$ of all malignant neoplasms in Poland, with the incidence of tumors being equal both in women and men. The data from the National Register of Neoplasms (in Polish: Krajowy Rejestr Nowotworów) shows that the frequency of brain tumors in adults increased twice in the recent 3 decades. ${ }^{1}$

There are 20-30 new cases of brain tumors recognized among children in Poland every year. After leukemia, brain tumors are the second most often diagnosed childhood cancer and account for $15 \%$ of all neoplastic diseases. In the last 20 years, the morbidity among people aged 0-19 remained on a constant level and brain tumors are the cause of death of $1 / 3$ of all children diagnosed with cancer. Only $25 \%$ of children that suffered from brain tumors survive 5 years and all of them suffer from late complications of both the main disease and side effects of its treatment. ${ }^{1}$

About 10,000 children who underwent cancer therapy live in Poland and require the state of their health to be monitored during the following years. ${ }^{2}$ The National Program for Fighting Cancer Diseases, founded and financed by the Ministry of Health, is aimed at cancer survivors, patients of the Department of Pediatrics, Oncology, Hematology and Diabetology, Medical University of Lodz. A thorough evaluation of state of children's health has been provided to detect late complications. The examinations in the fields of neurology, nephrology, cardiology have been carried out by specialists to diagnose endocrine disorders, growth impairment or secondary cancers. Since 2013, dental examinations have been performed in the patients and 75 cancer survivors were admitted to the Dental Institute, Medical University in Łódź in the following few years. Sixty-one of them had panoramic radiographic examination of their dentition.

The state of dentition of 4 children, who were cured from brain tumors, was described in this paper on the basis of dental and radiological examinations.

\section{Case reports}

\section{Patient 1 (P.C.)}

A girl (P.C.), born on May 9, 2000, was admitted to the Department of Pediatrics, Oncology, Hematology and Diabetology, Medical University of Lodz on September 10, 2004. At the beginning of the therapy she was 52 months old and the cancer therapy lasted for 20 months. A subtotal removal of the tumor was the first stage of treatment and the histopathological diagnosis of ependymoma was established. Then, the patient was treated according to the Polish protocol for treating brain tumors in children $>3$ years old (etoposide, vincristine, cisplatin, cyclophosphamide). Radiotherapy of the central nervous system (at a dose of $54 \mathrm{~Gy}$ ) was also performed. The disease is in remission, with a stable volume of the tumor (last followup in September, 2016).

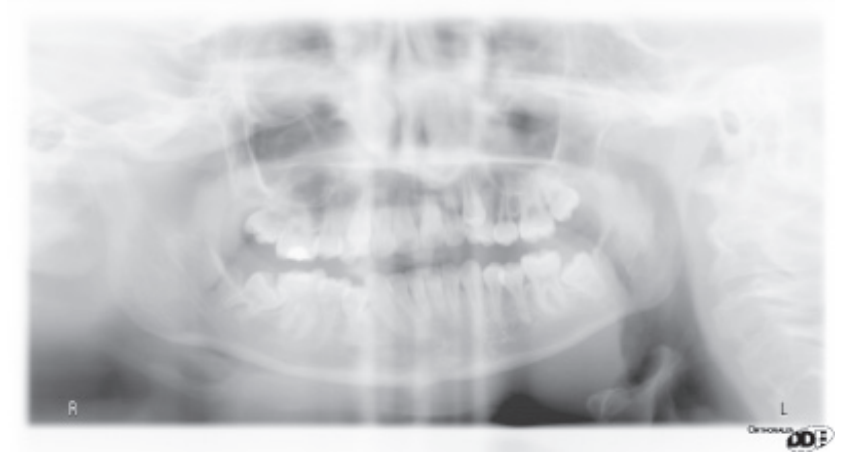

Fig. 1. (P.C.) Girl aged 12, 6 years after cancer therapy, short roots of premolars $15,25,34,35,44,45$ and taurodontic traits of teeth 16 and 26

At the time of dental investigations the girl was at the age of 12 years and 6 years passed since the end of the treatment. In a panoramic radiography (Fig. 1) changes in shape of the tooth roots were found in teeth: $15,25,34$, 35,44 and 45 and short roots with taurodontic traits of pulp chamber were found in teeth 16 and 26. The scores of DMFt and DMFs were 4 (2 teeth with caries and 2 teeth filled). The oral hygiene was quite good, with $\mathrm{OHI}=1$. The girl showed a bilateral anterior and posterior crossbite and rotations of teeth.

\section{Patient 2 (A.W.)}

A girl (A.W.), born on November 24, 1998, was admitted to the Department of Pediatrics, Oncology, Hematology and Diabetology, Medical University of Lodz on May 10, 2001. At the beginning of the therapy she was 29 months old and the cancer therapy lasted for 24 months. A total removal of the tumor was the first stage of the treatment and the histopathological diagnosis of medulloblastoma was established. Then, the patient was treated according to the Polish protocol for treating brain tumors in children $<3$ years old (etoposide, vincristine, cisplatin, cyclophosphamide). Due to the local relapse of the tumor, the second total removal of the tumor was performed. The girl was treated with chemotherapy for relapsed brain tumors (ICE protocol - ifosfamide, cisplatine, etoposide). Radiotherapy of the central nervous system (dose 54 Gy) was also performed. The disease stays in remission, with no tumor growth being detected (last follow-up in November, 2016).

In a panoramic radiography (Fig. 2) performed at the age of 14 years, 9 years after the end of therapy, the following dental anomalies were found: microdontic teeth $14,15,24$, agenesis of premolars 25,35 and changes in a crown shape of molars $17,27,37,47$. The opacities of enamel were also noted in most of the teeth. The score of dmft was 2 and dmfs was 8 (1 tooth with caries and 1 filled), whereas DMFt was 4 and DMFs was 5 (4 teeth with fillings). Oral Hygiene was poor, with $\mathrm{OHI}=2$. A bilateral, posterior crossbite was also found in the patient. 


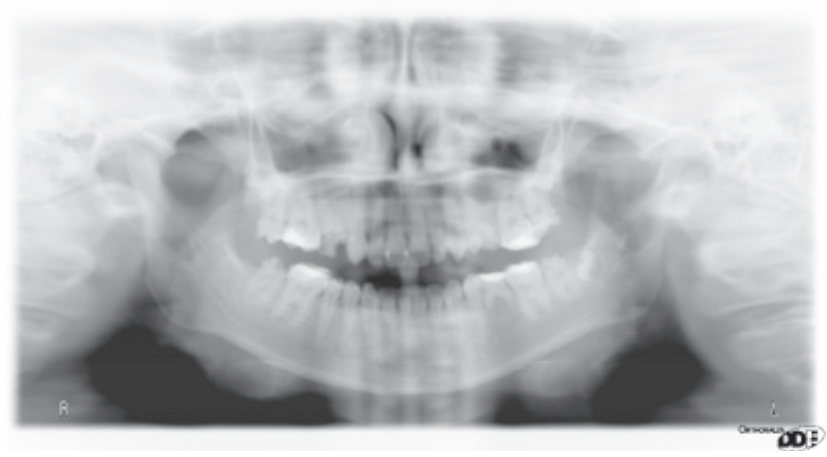

Fig. 2. (A.W.) Girl aged 14, 9 years after cancer therapy, microdontic 14, 15, 24 teeth, agenesis of premolars 25 and 35 and changes in the crown shape of molars 17, 27, 37 and 47

\section{Patient 3 (D.S.)}

A boy (D.S.), born on September 27, 2006, was admitted to the Department of Pediatrics, Oncology, Hematology and Diabetology, Medical University of Lodz on May 1, 2007. At the beginning of the therapy he was 6 months old, and the treatment lasted for 21 months. A total removal of the tumor was the first step of oncological treatment and the histopathological diagnosis of ependymoma anaplasticum III was established. Then the patient was treated according to the Polish protocol for treating brain tumors in children $<3$ years old (etoposide, vincristine, cisplatin, cyclophosphamide). Due to the young age of the child at the moment of chemotherapy cessation and no detectable signs of any local relapse of the tumor, radiotherapy of the central nervous system was not applied. The disease is in remission (last follow-up in August, 2016).

The patient had his teeth examined at the age of 6 years, 4 years after the end of therapy. Several microdontic teeth were found (all first premolars: 14, 24, 34 and 44) in panoramic radiography (Fig. 3). The $\mathrm{dmft}$ and dmfs scores were 1 ( 1 tooth with caries), whereas all permanent teeth were free from caries $(\mathrm{DMFt}=0)$. The patient had a normal occlusion and good oral hygiene $(\mathrm{OHI}=0)$.

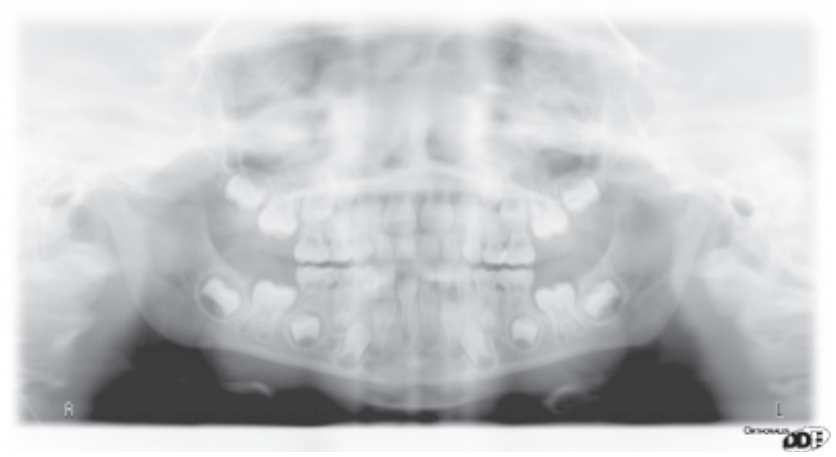

Fig. 3. (D.S.) Boy aged 6, 4 years after cancer therapy, microdontic first premolars: $14,24,34$ and 44

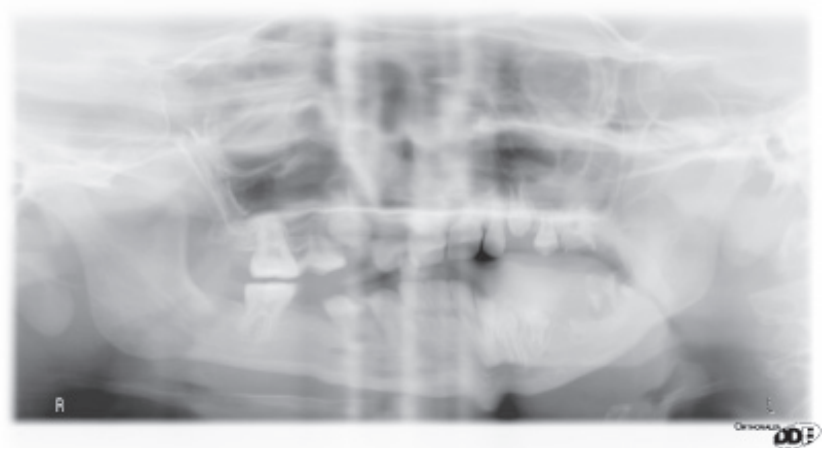

Fig. 4. (K.B.) Girl aged 8, 5 years after cancer therapy, agenesis of teeth 14, $15,35,45,17,27$; extracted molars 36 and 46 . There are also microdontic teeth: 22,23 and 24

\section{Patient 4 (K.B.)}

A girl (K.B.), born on September 17, 2004, was admitted to the Department of Pediatrics, Oncology, Hematology and Diabetology, Medical University of Lodz on March 12, 2007. The patient was 28 months old at the beginning of therapy, which lasted for 24 months. A subtotal removal of the tumor was the first stage of cancer treatment and the histopathological diagnosis of ependymoma was established. Then, patient was treated according to the Polish protocol for treating brain tumors in children $<3$ years old (etoposide, vincristine, cisplatin, cyclophosphamide). Because a stable volume of the tumor was established after chemotherapy, radiotherapy was not applied to the central nervous system. The disease is in remission, with a stable size of the tumor (last follow-up in August, 2016).

The patient was dentally examined 5 years after the cancer therapy, at the age of 8 years. Agenesis of teeth: $14,15,35,45,17,27$ was found in the patient and teeth 36 and 46 had been extracted. There were also microdontic teeth: 22, 23, 24 observed and lower incisors and canines were mobile.

The dmft score was 8 and dmfs was 32 (6 milk teeth had been extracted and 2 teeth had caries). The DMFt score was 6 and DMFs was 22 (2 teeth with caries, 2 extracted because of caries and 2 teeth with fillings).

The patient had mesioclusion and her oral hygiene was poor $(\mathrm{OHI}=3)$. Cooperation with the patient was limited.

\section{Discussion}

The children were treated according to the Polish protocols for treating brain tumors and all of them had dental anomalies observed later. It has been already proved that cancer survivors suffered more often from dental complications than healthy children. Missing and microdontic teeth, teeth with short roots or misshaped crowns, teeth with the opacities of enamel and higher caries rates have been significantly more often found in cancer survivors. ${ }^{3-5}$ 
It still remains unclear why some children after oncological treatment develop agenesis of teeth, while others develop microdontic teeth or other complications, as the correlation between the types of dental abnormalities and cancer treatment has not been explained so far. It is suspected that the type of abnormality might depend on the stage of tooth development at the moment of applying the treatment. ${ }^{5}$ This is in accordance with our observations. The youngest of our 4 patients started the therapy at the age of 6 months and had 4 microdontic first premolars, while the oldest patient, who started the therapy at the age of 52 months, had only changes in the shape of roots. The worst dental complications were found in a girl with a relapse of tumor, who was treated with radiotherapy of head $>54$ Gy. She had both missing and microdontic teeth and her tooth crowns of molars were misshaped as well.

Harmful effects of head or neck radiotherapy during cancer treatment on oral state of patients have been extensively described and discussed in the literature. ${ }^{6,7}$ Dysfunction of salivary glands, followed by xerostomia, may lead to increased susceptibility to oral infections, sleep disturbances and difficulties in eating or even speaking. In long term prospects, decreased salivary flow can lead to enamel demineralization and increased caries. ${ }^{8}$

In patients at the developmental age, radiotherapy can also directly disturb the mitotic activity of odontoblasts, which results in the formation of "osteodentin" instead of normal dentine and indirectly affects the process of enamel formation. ${ }^{9,10}$ Lower level of phosphorylated phosphoprotein in the damaged dentine may inhibit the process of mineralization of the enamel, as a close spatial relationship between enamel and the crystals of calcified dentin collagen fibrils has been observed. ${ }^{11}$ A multivariate analysis of self-reported dental state of 9,308 cancer survivors in the USA has revealed that radiation exposure $(\geq 20 \mathrm{~Gy}$ ) was associated with an increased risk of dental abnormality. ${ }^{12}$

High-dose radiotherapy (of more than 54 Gy) can be applied in the treatment of brain tumors in older children. Two of the patients reported in this paper were treated with radiotherapy of the central nervous system at the age $>3$, which is still a very young children, as odontogenesis and active mineralization of hard tooth tissues takes place at that time. This is why white opacities, which were the result of enamel disturbances, were noted in a girl with relapsed disease and the crowns of her second molars were misshaped, with the enamel flaking out.

The younger the age of cancer patients, the higher the risk of dental complications. Among 55 children after stem cell transplantation, the younger age $(<5$ years) was found to be a strong risk factor for tooth abnormalities. ${ }^{13}$ It was also found that in children $<5$ years of age, the risk of abnormalities depended on the dose of alkylating agent used in the therapy. ${ }^{12}$

Chemotherapeutics used in cancer therapy have already been proved to interrupt the process of odontogenesis in children. In the investigated patients, the following drugs were used: etoposide, vincristine, cisplatin and cyclophosphamide. Among those, vincristine has been most often described as highly pathogenic for tooth development. ${ }^{10}$ The "in vitro" experiment on tooth development with the use of the organ culture model showed that induction of mitotic arrests at the cervical loop and in the inter-cuspal regions was due to the toxic effect of vincristine. Mineralization decreased as the dose was increased and the highest doses were cytotoxic to most cells in the developing tooth germ, while the lowest doses did not induce pathological changes. ${ }^{14}$

It was also found that children who received a cumulative dose of cyclophosphamide $>7500 \mathrm{mg} / \mathrm{m}^{3}$ during the cancer therapy had significantly more teeth with short roots than cancer survivors who got none or lower doses. ${ }^{15}$ Earlier experimental studies on rat teeth showed that wide cell-free areas, which later turned into osteodentin, appeared in the third molar of animals after injections of cyclophosphamide at the dose of $30 \mathrm{mg}$ per $\mathrm{kg}$ of body weight. The injections were made on the $10^{\text {th }}$ and $13^{\text {th }}$ day of age and the sites affected by changes were related to the developmental stage of tooth germ. ${ }^{16}$ Also, in the study by Kawakami et al., several injections of cyclophosphamide $(100 \mathrm{mg} / \mathrm{kg}$, i.p.) have led to the disturbance in the length and shape of roots of the first molars in 12-day-old mice. ${ }^{17}$

In our patients, brain tumors were surgically removed at the first stage of treatment. In some cases, surgery of head in cancer therapy may also lead to the disturbance in occlusion. We found that 3 out of 4 patients had malocclusion: 2 patients had crossbites and 1 had mesioclusion. Those anomalies were probably not related to the applied cancer treatment, since mesioclusion and crossbite are the most often found malocclusions among Polish children. ${ }^{18}$ However, a crossbite concerning especially the deciduous teeth is quite often associated with a diet that is too soft. The children during cancer therapy had incidents of acute inflammation of the oral mucosa, which prevented them from eating hard food, which might later turn into a part of their nutritional habits. Nutritional disorders of children ingesting only small amount of semi-fluid or fluid food during their long-lasting anticancer therapies, are also a matter of concern to oncologists. ${ }^{19}$

Another girl with malocclusion had several teeth extracted and it was difficult to precisely determine which teeth were missing because of cancer therapy and which had been extracted during previous dental treatment. However, the condition of the missing molars led to a high number of dental problems, which included pathological mobility of overloaded lower one-rooted teeth.

Our patients also had problems with maintaining good oral hygiene and the scores of caries among them were relatively high. They were not given an additional fluoride prophylaxis, neither during nor after the cancer treatment. Despite their young age at the dental check-up: 14, 12, 8 and 6 years, all children except for the young- 
est one had permanent teeth with active caries lesions, either extracted or filled. That might be partly due to adverse circumstances caused by the cancer therapy, which intensified processes of demineralization in the enamel. Hsieh et al. found that half of the recipients of childhood antineoplastic therapy had low $(0.7-1.0 \mathrm{~mL} / \mathrm{min})$ or very low $(<0.7 \mathrm{~mL} / \mathrm{min})$ saliva flow. ${ }^{15}$

On the other hand, authors indicated that a higher incidence of caries in cancer survivors was often related to the lack of proper caries prophylaxis during and after treating the main disease. ${ }^{10}$ Cancer patients, who were included in proper dental care programs, did not differ in terms of caries scores from their healthy peers. ${ }^{20}$

\section{Conclusion}

Cancer patients cured from brain tumors should be covered with special dental care and treatment in order to avoid late dental complications of antineoplastic therapy.

\section{References}

1. Wojciechowska U, Didkowska J. Morbidity and mortality of neoplasms in Poland. National Register of Neoplasms. The Maria Skłodowska-Curie Memorial Cancer Centre and Institute of Oncology. http://onkologia.org.pl/mozg-c71/. Published June 2013. Updated December 2016. Accessed May 20, 2017 [in Polish].

2. Szymborski J, Didkowska J, Wojciechowska U. Malignant neoplasms in children and adolescents in Poland. In: Potrykowska A, Strzelecki Z, Szymborski J, Witkowski J, ed. Cancer incidence and mortality versus the demographic situation of Poland. ed. Warszawa, 2014:117-119 [in Polish].

3. Krasuska-Sławińska E, Brożyna A, Dembowska-Bagińska B, Olczak-Kowalczyk D. Antineoplastic chemotherapy and congenital tooth abnormalities in children and adolescents. Contemp Oncol (Pozn). 2016;20:394-401.

4. Pedersen LB, Clausen N, Schroder H, Schmidt M, Poulsen S. Microdontia and hypodontia of premolars and permanent molars in childhood cancer survivors after chemotherapy. J Paediatr Dent. 2012;22:239-243.

5. Proc P, Szczepańska J, Skiba A, Zubowska M, Fendler W, Młynarski W. Dental anomalies as late adverse effect among young children treated for cancer. Cancer Res Treat. 2016;48:658-667.

6. Effinger KE, Migliorati CA, Hudson M. Oral and dental late effects in survivors of childhood cancer: A Children's Oncology Group report. Support Care Cancer, 2014;22:2009-2019.

7. Tolentino ES, Centurion BS, Ferreira LHC, Souza AP, Damante JH, Rubira-Bullen IRF. Oral adverse effects of head and neck radiotherapy: literature review and suggestion of a clinical oral care guideline for irradiated patients. J Appl Oral Sci. 2011;19:448-454.

8. Jensen SB, Pedersen AM, Vissink A. A systematic review of salivary gland hypofunction and xerostomia induced by cancer therapies: prevalence, severity and impact on quality of life. Support Care Cancer, 2010;18:1039-1060.

9. Collett WK, Thonard JC. The effect of fractional radiation on dentinogenesis in the rat. J Dent Res. 1965;44:84-90.

10. Gawade PL, Hudson MM, Kaste SC. A systematic review of dental late effects in survivors of childhood cancer. Pediatr Blood Cancer. 2014;61:407-416.

11. Arsenault $A L$, Robinson BW. The dentino-enamel junction: A structural and microanalytical study of early mineralization. Calcif Tissue Int. 1989;45:111-121.

12. Kaste SC, Goodman P, Leisenring W, Stoval M. Impact of radiation and chemotherapy on risk of dental abnormalities: A report from the childhood cancer survivor study. Cancer, 2009;115:5817-5827.
13. Holtta P, Alaluusua S, Saarinen-Pihkala UM, Peltola J, Hovi L. Agenesis and microdontia of permanent teeth as late adverse effects after stem cell transplantation in young children. Cancer, 2005;103:181-190.

14. Lyaruu DM, van Duin MA, Bervoets TJ, Wöltgens JH, Bronckers AL. Effects of vincristine on the developing hamster tooth germ in vitro. Connect Tissue Res. 1995;32:281-289.

15. Hsieh SGSH, Hibbert S, Shaw P, Ahern V, Arora M. Association of cyclophosphamide use with dental developmental defects and salivary gland dysfunction in recipients of childhood antineoplastic therapy. Cancer, 2011;117:2219-2227.

16. Näsman M, Hammarstrom L. Influence of the antineoplastic agent cyclophosphamide on dental development in rat molars. Acta Odontol Scand. 1996;54:287-294.

17. Kawakami T, Nakamura Y, Karibe H. Cyclophosphamide-induced morphological changes in dental root development of ICR mice. PLOS ONE, 2015;10:e0133256.

18. Piątkowska D, Woźniak K, Lipski M. Systematic review of incidence of malocclusion in Poland based on original studies published during the years 2000-2010. Magazyn Stomatol. 2012;22:4,121-126 [in Polish].

19. Gara-Rucińska M, Lehmann-Kalata AP, Łysenko L. Nutritional problems in head and neck cancer patients. Dent Med Probl. 2016;53:401-407.

20. Cubukcu CE. Dental health indices of long-term childhood cancer survivors who had oral supervision during treatment: A case control study. Pediatr Hematol Oncol. 2008;25:638-646. 